\title{
Detecção de sílica em folha bandeira de trigo
}

\author{
Silica detection in the flag leaf of wheat
}

\author{
Felipe Aranha de Andrade'; Célia Guadalupe Tardeli de Jesus Andrade²; \\ Édison Miglioranza ${ }^{3 *}$
}

\section{Resumo}

O silício é considerado um elemento benéfico às plantas, podendo trazer incrementos na produtividade e sanidade de diversas culturas. Nos vegetais, acumula-se principalmente nas áreas de máxima transpiração. Este trabalho teve por objetivo comparar o acúmulo de silício nas folhas bandeira de diferentes genótipos de trigo (Triticum aestivum L.), com o auxílio da Microscopia Eletrônica de Varredura (MEV). O experimento foi conduzido a campo, durante o ano agrícola de 2010, aonde foram utilizados oito genótipos de trigo (cultivares BRS 208, IPR 85, BRS Pardela, BRS 210, IPR 130, CD 104, BRS 220 e a linhagem WT 07106). Aos três meses após a semeadura, retiraram-se amostras das folhas para a análise de silício em MEV e espectroscopia de energia dispersiva de raios-X (EDS). Todos os genótipos avaliados acumularam corpos silicosos em suas epidermes foliares, sendo que esses corpos apresentaram formato arredondado e deposição diferenciada entre os diversos genótipos.

Palavras-chave: Silício, Triticum aestivum, corpos silicosos, microscopia eletrônica de varredura, espectroscopia de energia dispersiva de raios- $\mathrm{X}$

\begin{abstract}
Silicon is considered a beneficial element to plants and may increase productivity and health of many crops. In plants, silicon accumulates mainly in the areas of maximum transpiration. This study aimed to investigate and compare silicon accumulation in flag leaves of different genotypes of wheat (Triticum aestivum) with the aid of scanning electron microscopy (SEM). The experiment was conducted in the field during the growing season 2010, eight wheat genotypes (BRS 208, RPI 85, BRS Pardela, BRS 210, RPI 130, CD 104, BRS 220 and WT 07106 lineage) were used. Three months after sowing, the samples were collected from the leaves to perform the silicon analysis by SEM and energy dispersive X-ray (EDS). All genotypes accumulated silica bodies in their leaf epidermis, the bodies had a rounded shape and were deposited differently from one genotype to another.

Key words: Silicon, Triticum aestivum, silica bodies, scanning electron microscopy, energy dispersive $\mathrm{X}$-ray detector

\footnotetext{
${ }^{1}$ Eng $^{\mathrm{o}}$ Agr $^{\mathrm{o}}$, Mestrando em Agronomia do Dept ${ }^{\circ}$ de Agronomia, Universidade Estadual de Londrina, UEL, Centro de Ciências Agrárias, Londrina, PR. E-mail: felipearanhaa@hotmail.com

${ }^{2}$ Prof $^{\mathrm{a}}$. Dra ${ }^{\mathrm{a}}$. do Dept ${ }^{\mathrm{o}}$ de Biologia Geral, UEL/Centro de Ciências Biológicas, Londrina, PR. E-mail: cgtardeli@uel.br

${ }^{3}$ Prof. Dr. do Dept ${ }^{\circ}$ de Agronomia, UEL/CCA, Londrina, PR. E-mail: emiglior@uel.br

${ }^{*}$ Autor para correspondência
} 


\section{Introdução}

O silício é considerado um elemento não essencial e não tóxico para as plantas, podendo contribuir favoravelmente para o desempenho de diversas culturas. Sendo assim, pode incrementar a produtividade; regular a perda de água; melhorar a taxa fotossintética; aumentar a rigidez da estrutura dos tecidos; reduzir os índices de acamamento; diminuir os danos causados pela geada; aumentar a resistência de várias espécies, principalmente as monocotiledôneas, às pragas e às doenças; além de diminuir o efeito tóxico de ferro e manganês às raízes (KORNDÖRFER; DATNOFF, 1995; DATNOFF; RODRIGUES; SEEBOLD, 2007).

Os vegetais absorvem o silício da solução do solo, juntamente com água, na forma de ácido monossilícico $\left(\mathrm{H}_{4} \mathrm{SiO}_{4}\right)$, através do fluxo de massa. Este elemento acumula-se principalmente nas áreas de máxima transpiração, como folhas, tricomas e espinhos, como ácido silícico polimerizado, na forma de sílica amorfa. Dentre as plantas cultivadas, as gramíneas como o trigo, por exemplo, são consideradas como boas acumuladoras de silício, pois possuem teor foliar acima de 1\%. Quando as plantas acumulam um teor de silício menor que 0,5\% são consideradas não acumuladoras (MA; MIYAKE; TAKAHASHI, 2001).

Deren, Glaz e Snyder (1993) trabalhando com 52 genótipos de cana-de-açúcar cultivados em solos arenosos e orgânicos, obtiveram valores de 6,4 a $10 \mathrm{~g} \mathrm{~kg}^{-1}$ de silício nas folhas. Concluindo assim, que há grande variabilidade entre uma cultivar e outra quanto à absorção deste elemento. Fato que corrobora com os estudos realizados por Korndörfer et al. (2000) aonde foram utilizados três genótipos de cana-de-açúcar em Argissolo Vermelho-Amarelo, observando assim diferenças entre genótipos: 7,6; 10,4 e 11,4 $\mathrm{g} \mathrm{kg}^{-1}$ de silício para RB 72 454, SP 791011 e SP 71-6163, respectivamente.

Segundo Sávio et al. (2011) avaliando a utilização de três diferentes fontes de silício sobre as características agronômicas e conteúdos foliares de Si em Brachiaria. decumbens cv. Basilisk e Panicum maximum cv. Mombaça observaram que as duas espécies forrageiras testadas, diferiram quanto ao acúmulo de Si na parte aérea, tendo $B$. decumbens apresentando maiores valores, quando comparado com P. maximum.

O acúmulo de silício em folhas novas de trigo ocorre predominantemente na epiderme abaxial, por outro lado, em folhas velhas, esta deposição é verificada em ambas as epidermes. Hodson, Sangster (1988) analisando células buliformes e epidérmicas, parede dos tricomas, esclerênquima epidermal e subepidermal, mesofilo e diversos tipos de sistemas vasculares presentes nas folhas, detectaram pouca quantidade de silício nessas estruturas

De maneira geral, o silício pode ser encontrado em boas quantidades, quase sempre na forma de sílica gel, em locais como vacúolos, citoplasma e sobre o tonoplasto. Além do mais, na cultura do trigo a absorção deste é mais rápida do que a da água, mostrando desta forma que há um mecanismo ativo de transporte, por meio das membranas das células das raízes. Aliás, tal elemento concentra-se dentro da célula, no xilema na sua forma solúvel (CASEY et al., 2004).

A transpiração, bem como o crescimento (DUDA; GUTSER; SCHMIDHALTER, 2001) e disponibilidade de silício no substrato de cultivo, geralmente determinam a absorção e acumulação deste elemento na parte aérea das plantas de trigo. Além disso, o fato do aumento de temperatura aumentar a transpiração faz com que se eleve o teor de silício nos tecidos de tal cultura (SU et al., 2002). Em plântulas de trigo foi verificado que os depósitos de silício ocorrem nos tecidos estruturais, vasculares, de armazenamento e na epiderme. Além do mais, o processo de silicificação em gramíneas geralmente ocorre nas raízes e na parte aérea, em locais como colmos, folhas e, com maior intensidade, nas inflorescências. Quando os sítios da endoderme radicular encontram-se silicificados a maior parte do silício é transportada para a parte 
aérea da planta (SANGSTER; HODSON; TUBB, 2001).

Considerando que plantas com maior acúmulo de silício podem ser favorecidas pelos seus efeitos benéficos e que as cultivares de trigo podem acumulá-lo diferentemente, este trabalho teve por objetivo comparar o acúmulo de silício nas folhas de diferentes genótipos de trigo, sob as mesmas condições de cultivo. Para tanto, utilizou-se a espectroscopia de energia dispersiva de raios-X (EDS) acoplado ao Microscópio Eletrônico de Varredura (MEV).

\section{Material e Métodos}

O experimento foi conduzido a campo, durante o ano agrícola de 2010, no município de Londrina, localizado na região Norte do Paraná, que se encontra a $23^{\circ} 11^{\prime}$ de latitude Sul, $51^{\circ} 10^{\prime}$ de longitude Oeste de Greenwich, com altitude de 600 m. O clima da região, segundo a classificação de Köppen, é Cfa, ou seja, clima subtropical com temperatura média no mês mais frio inferior a 18 ${ }^{\circ} \mathrm{C}$ (mesotérmico) e temperatura média no mês mais quente acima de $22{ }^{\circ} \mathrm{C}$, com verões quentes, geadas pouco freqüentes e tendência de concentração das chuvas nos meses de verão, contudo sem estação seca definida (INSTITUTO AGRONÔMICO DO PARANÁ, 2010). No mês de maio de 2010, período em que foi implantado o experimento, ocorreu uma precipitação média de 71,4 mm; em junho $18 \mathrm{~mm}$; julho $33,1 \mathrm{~mm}$ e agosto $30,4 \mathrm{~mm}$.

$\mathrm{Na}$ área do experimento o solo foi classificado como Latossolo Vermelho distroférrico, horizonte A moderado e textura muito argilosa, com $787 \mathrm{~g}$ $\mathrm{kg}^{-1}$ de argila (EMBRAPA, 1997). A referida área vinha sendo manejada no sistema de plantio direto sendo que a cultura anterior foi soja. Previamente à instalação dos experimentos foram coletadas amostras de solo das áreas experimentais para análise química. Os resultados obtidos foram os seguintes: na camada de $0-20 \mathrm{~cm}: \mathrm{pH}=4,80 ; \mathrm{H}+\mathrm{Al}$ $=6,02 \mathrm{cmolc} / \mathrm{dm}^{3} ; \mathrm{Al}=0,26 \mathrm{cmolc} / \mathrm{dm}^{3} ; \mathrm{K}=0,56$ cmolc $/ \mathrm{dm}^{3} ; \mathrm{Ca}+\mathrm{Mg}=5,67 \mathrm{cmolc} / \mathrm{dm}^{3} ; \mathrm{P}=14,12$ $\mathrm{mg} / \mathrm{dm}^{3} ; \mathrm{C}=2,48 \mathrm{~g} / \mathrm{dm}^{3}$; Soma de Bases $=6,23$; $\mathrm{CTC}=12,26 ; \mathrm{V} \%=50,84$. Na camada de $20-40 \mathrm{~cm}$ os resultados foram os seguintes: $\mathrm{pH}=4,96 ; \mathrm{H}+\mathrm{Al}$ $=6,54 \mathrm{cmolc} / \mathrm{dm}^{3} ; \mathrm{Al}=0,30 \mathrm{cmolc} / \mathrm{dm}^{3} ; \mathrm{K}=0,44$ cmolc $/ \mathrm{dm}^{3} ; \mathrm{Ca}+\mathrm{Mg}=4,28 \mathrm{cmolc} / \mathrm{dm}^{3} ; \mathrm{P}=11.02$ $\mathrm{mg} / \mathrm{dm}^{3} ; \mathrm{C}=4,69 \mathrm{~g} / \mathrm{dm}^{3}$; Soma de Bases $=4,71$; $\mathrm{CTC}=11,25 ; \mathrm{V} \%=41,88$.

A adubação de nitrogênio, fósforo e potássio (NPK) na semeadura foi realizada conforme os resultados da análise de solo, seguindo as Indicações Técnicas da Comissão Brasileira de Pesquisa de Trigo e Triticale para o Estado do Paraná (EMBRAPA, 2008). Foram aplicados $24 \mathrm{~kg}$ ha $^{-1}$ de N, $84 \mathrm{~kg} \mathrm{ha}^{-1}$ de $\mathrm{P}_{2} \mathrm{O}_{5}$ e $48 \mathrm{~kg} \mathrm{ha}^{-1}$ de $\mathrm{K}_{2} \mathrm{O}$, na semeadura.

As sementes foram tratadas com o fungicida $\operatorname{Baytan}^{\circledR}$ (Triadimenol), na dose de $3 \mathrm{~mL} \mathrm{~kg}^{-1}$ de semente, e com o inseticida Gaucho ${ }^{\circledR}$ (Imidacloprid), na dose de $1 \mathrm{~mL} \mathrm{~kg}^{-1}$ de semente. A semeadura foi realizada no dia 05/05/2010 visando a obtenção de uma densidade de aproximadamente 325 plantas $\mathrm{m}^{-2}$. Foram semeados oito genótipos de trigo a saber: BRS 208, IPR 85, BRS Pardela, BRS 210, IPR 130, CD 104, BRS 220 e WT 07106 ,

Cada parcela experimental era constituída de 10 linhas, com seis metros de comprimento e com espaçamento entre linhas de $20 \mathrm{~cm}$. Foi considerada como área útil de cada parcela experimental as seis linhas centrais, desprezando-se $0,75 \mathrm{~m}$ nas extremidades, totalizando $5,4 \mathrm{~m}^{2}$. A emergência de plântulas ocorreu seis dias após a semeadura. A adubação de cobertura, fornecendo $50 \mathrm{~kg} \mathrm{ha}^{-1}$ de nitrogênio, na forma de sulfato de amônio, foi realizada aos 16 dias após a emergência, correspondendo ao início do perfilhamento. Sendo que, cerca de quatro horas após a adubação nitrogenada, foi efetuada uma irrigação de aproximadamente $18 \mathrm{~mm}$.

Os tratos culturais foram realizados de acordo com as Indicações Técnicas da Comissão Brasileira de Pesquisa de Trigo e Triticale para o Estado do 
Paraná (EMBRAPA, 2008). Para o controle de plantas daninhas foi realizada uma aplicação da mistura do herbicida Basagran ${ }^{\circledR}$ (Bentazona) na dose de 1,2 $\mathrm{L} \mathrm{ha}^{-1}$ com Assist $^{\circledR}$ na dose de $0,5 \mathrm{~L}$ $h^{-1}$. A aplicação de fungicidas foi como controle erradicativo no aparecimento dos primeiros sintomas, sendo a área experimental monitorada semanalmente. Dessa forma, foi realizada uma aplicação de Rival ${ }^{\circledR}$ (Tebuconazole) e outra aplicação de Nativo ${ }^{\circledR}$ (Trifloxistrobina + Tebuconazol) na dose de $0,75 \mathrm{~L} \mathrm{ha}^{-1}$.

Para análise foliar em microscopia eletrônica de varredura foram coletadas, no dia 05 de agosto de 2010, aleatoriamente na área útil de cada parcela, a folha bandeira de uma planta de cada cultivar. Essas folhas foram cortadas em suas partes centrais e imersas em solução fixadora contendo $5 \%$ de formol, $90 \%$ de álcool etílico e 5\% de ácido acético (F.A.A) por $24 \mathrm{~h}$ à temperatura ambiente. Após esse tempo, foram desidratadas em séries crescentes de etanol $(70 \%, 80 \%, 90 \%, 100 \%)$ e secas ao ponto crítico em $\mathrm{CO}_{2}$ (Bal Tec CPD 030). Em seguida, as amostras foram coladas nos "stubs" com a superfície adaxial voltada para cima e foram recobertas com carbono, utilizando-se o Sputter coater Bal-Tec SCD 050. Para a detecção da presença de silício, as amostras foram analisadas por espectroscopia de energia dispersiva (EDS-Oxford), software INCA, acoplado ao microscópio eletrônico de varredura
(MEV) FEI Quanta 200. Em seguida, foram recobertas com uma camada de ouro de $25 \mathrm{~nm}$ de espessura (Sputter coater Bal-Tec SCD 050) para análise ao microscópio eletrônico de varredura FEI Quanta 200.

\section{Resultados e Discussão}

Ao MEV foram observadas, na epiderme adaxial das folhas bandeira de trigo, estruturas com formas arredondadas que apresentavam distribuição diferencial na superfície foliar entre os vários genótipos (Figura 1).

A análise por EDS revelou, nessas folhas, a presença de diversos elementos químicos, tais como silício, carbono, oxigênio, ferro, sódio, alumínio, enxofre (Figura 2A). Nas estruturas arredondadas (Figura 2B), por outro lado, foi detectada uma maior concentração percentual de silício em relação aos outros elementos. Assim, a análise por EDS comprovou que essas estruturas eram corpos silicosos. A presença de elementos, como carbono pode ser proveniente do recobrimento das amostras e, carbono e oxigênio fazem parte da composição orgânica da planta. O alumínio, por sua vez, pode ser proveniente de contaminação ambiental, pois testes realizados paralelamente ao experimento evidenciaram que sua origem era da amostra de planta analisada. 
Figura 1. As eletromicrografias ilustram a distribuição de corpos silicosos na epiderme adaxial da folha bandeira de trigo dos cultivares. A) BRS 208. B) BRS 210. C) BRS 220. D) CD 104. E) IPR 85. F) BRS Pardela. G) IPR 130 e H) linhagem WT 07106.

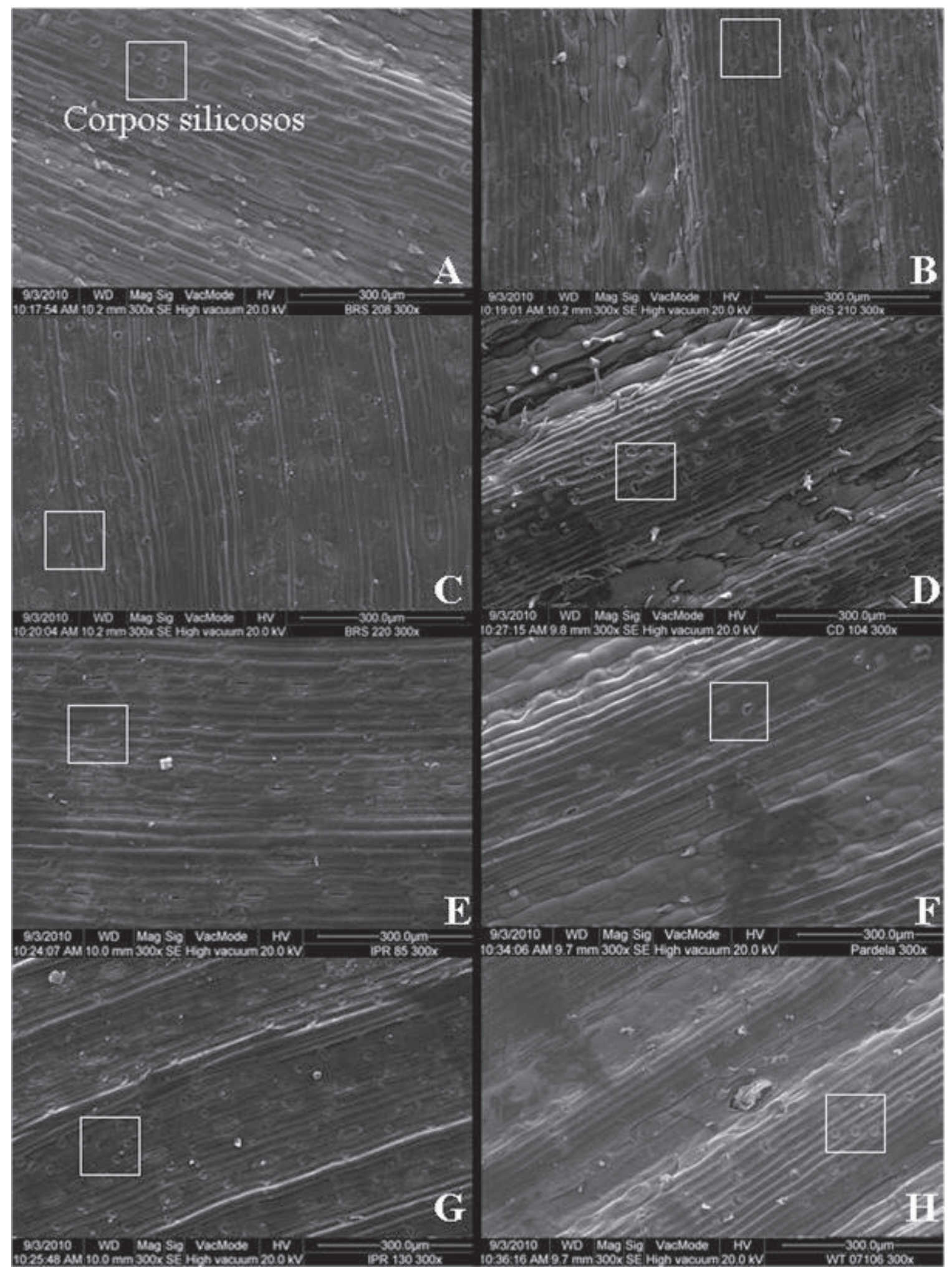

Fonte: Elaboração dos autores. 
Figura 2. A) Espectro dos elementos presentes na epiderme adaxial da folha bandeira de trigo detectados por EDS. B) Espectro de elementos obtidos de um corpo silicoso. Note a concentração percentual de silício em relação aos outros elementos.

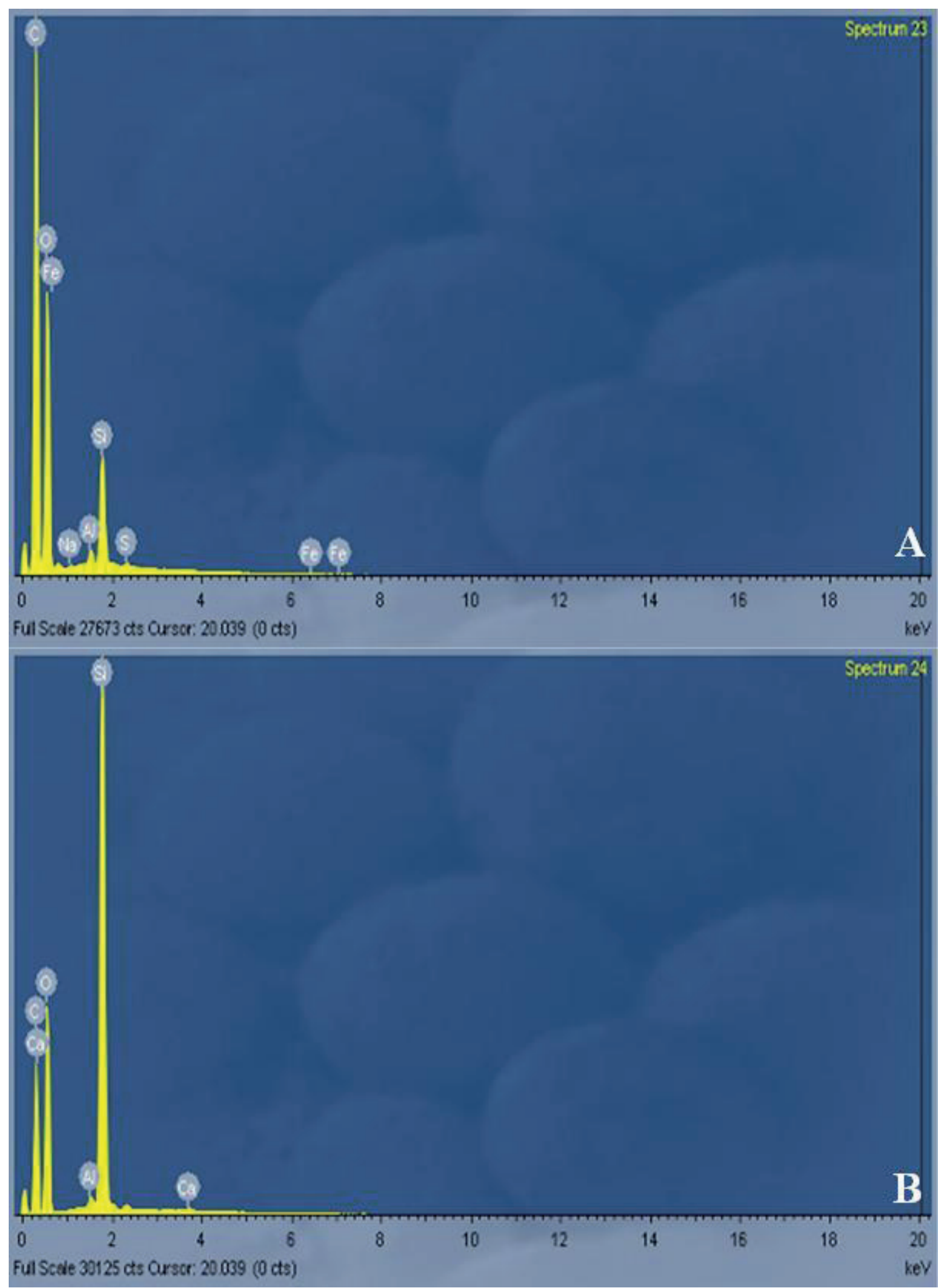

Fonte: Elaboração dos autores. 
Nos genótipos BRS-208 (Figura 1A), CD-104 (Figura 1D) e BRS-Pardela (Figura1F) os corpos silicosos estavam organizados em faixas, entre fileiras de estômatos. Nos genótipos BRS-210 (Figura 1B), BRS-220 (Figura 1C), IPR-85 (Figura 1E) e IPR-130 (Figura 1G) os corpos silicosos estavam dispersos por toda a superfície foliar, sem uma localização preferencial. Na linhagem WT 07106 (Fig. 1H), por outro lado, os corpos silicosos estavam dispersos entre fileiras de estômatos. Estes dados corroboram aqueles obtidos por outros pesquisadores (DEREN, DATNOFF; SNYDER, 1992; WINSLOW, 1992), que relatam a existência de alta variabilidade genética na capacidade de absorção e translocação de silício entre as cultivares.

Outro fator importante, que evidencia as diferenças entre o acúmulo e a deposição do silício na parte aérea entre os diversos genótipos, é a capacidade diferencial que as raízes têm em absorver esse elemento, podendo sua concentração variar entre 1 e $100 \mathrm{~g} \mathrm{~kg}^{-1}$ de matéria seca (TAKAHASHI; MA; MIYAKE, 1990).

Interessantemente, as folhas acumularam corpos silicosos, mesmo sem terem recebido tratamento prévio com silício. Isto pode ser devido à fase sólida dos nossos solos, que é composta basicamente por minerais de alumínio e sílica e pelo fato de serem as gramíneas boas acumuladoras deste elemento.

As folhas bandeira foram escolhidas para a detecção de sílica porque contribui com cerca de $30-50 \%$ dos assimilados que formam os grãos (SYLVESTER-BRADLEY; SCOTT e WRIGHT, 1990). Ainda, de acordo com os estudos de Dayanandam, Kaufman e Frakin (1983), há maiores teores de silício em regiões aonde ocorrem maiores perda de água, como na epiderme foliar, por exemplo.

Pozza et al. (2004) comparando cultivares de café sem adubação com silício e com adubação de silicato de cálcio, observaram que as cultivares adubadas apresentavam maior quantidade de corpos silicosos na superfície abaxial da folha. Além do mais, as cultivares tratadas mostraram distribuição uniforme deste elemento na superfície foliar. $\mathrm{Na}$ testemunha, que não recebeu tratamento, o silício foi encontrado de forma localizada.

Domiciano et al. (2010) estudando adubação com silício nas cultivares de trigo, BR-18 e BRS-208, detectaram que a concentração de sílica nas folhas bandeira das plantas adubadas foi 90,5\% superior ao resultado obtido nas plantas não supridas com esse elemento.

A comparação dos resultados obtidos neste trabalho com aqueles da literatura, mostra a necessidade de estudos utilizando aplicação de silício, que permitam estabelecer se o tratamento com este elemento leva a um aumento na quantidade e a uma alteração na distribuição dos corpos silicosos.

\section{Conclusões}

Todos os genótipos de trigo analisados acumularam corpos silicosos, sendo que estes apresentaram formas arredondadas.

Os corpos silicosos depositaram-se em três diferentes padrões, em faixas entre fileiras de estômatos; dispersos por toda a superfície foliar e dispersos entre fileiras de estômatos.

A metodologia utilizada foi eficiente em estabelecer a morfologia, a distribuição e mesmo a composição dos corpos silicosos.

Novos estudos devem ser realizados, no entanto, que permitam comparar se a adubação prévia com silício pode levar a um comportamento diferente desse elemento no estabelecimento dos corpos silicosos.

\section{Referências}

CASEY, W. H.; KINRADE, S. D.; KNIGHT, C. T. G.; RAINS, D. W.; EPSTEIN, E. Aqueous silicate complexes in wheat, Triticum aestivum L. Plant Cell and Environment, Oxford, v. 27, n. 1, p. 51-54, jan. 2004. 
DATNOFF, L. E.; RODRIGUES , F. A.; SEEBOLD, K. W. Silicon and plant nutrition. In: DATNOFF, L. E.; ELMER, W. H.; HUBER, D. M. (Ed.). Mineral nutrition and plant disease. Saint Paul MN: APS Press, 2007. p. 233-246.

DAYANANDAM, P.; KAUFMAN, P. B.; FRAKIN, C. I. Detection of silica in plants. American Journal Botany, California, v. 70, n. 7, p. 1079-1084, 1983.

DEREN, C. W.; GLAZ, B.; SNYDER, G. H. leaftissue silicon content of sugarcane genotypes grown on Everglades Histossols. Journal of Plant Nutrition, Athens, v. 16, p. 2273-2280, 1993.

DEREN, L. W.; DATNOFF, L. E.; SNYDER, G. H. Variable silicon content of rice cultivars grown on everglades histosols. Journal of Plant Nutrition, Athens, v. 15, n. 11, p. 2363-2368, nov. 1992.

DOMICIANO, G. P.; RODRIGUES, F. A.; MOREIRA, W. R.; OLIVEIRA, H. V.; VALE, F. X. R.; FILHA, M. S. X. Silício no progresso da mancha marrom na folha bandeira do trigo. Tropical Plant Pathology, Viçosa, v. 35, n. 3, p. 186-189, maio/jun. 2010.

DUDA, R.; GUTSER, R.; SCHMIDHALTER, U. Characterizing site specific differences in water availability. Plant Nutrition, Philadelphia, v. 92, n. 6, p. 390-391, 2002.

EMPRESA BRASILEIRA DE PESQUISA AGROPECUÁRIA - EMBRAPA. Centro Nacional de Pesquisa de Solos (Rio de Janeiro, RJ). Manual de métodos de análise de solo. 2. ed. Rio de Janeiro: Embrapa, 1997. 212 p. (Embrapa-CNPS. Documentos, $1)$.

Informações técnicas para a safra 2008: trigo e triticale. In: REUNIÃO DA COMISSÃO BRASILEIRA DE PESQUISA DE TRIGO E TRITICALE, 1., 2007, Londrina. Anais... Londrina: Embrapa, 2008. 147 p. (Embrapa Soja. Documentos, 301).

HODSON, M. J.; SANGSTER, A. G. Observations on the distribuition of mineral elements in the leaf of wheat (Triticum aestivum L.), with particular reference to silicon. Annuals of Botany, London, v. 62, n. 5, p. 463471, nov. 1988.

INSTITUTO AGRONÔMICO DO PARANÁ - IAPAR. Cartas climáticas do Estado do Paraná. Disponível em: $\quad<$ http://200.201.27.14/Sma/Cartas_Climaticas/ Classificacao_Climatica.htm>. Acesso em: 20 out. 2010.
KORNDÖRFER, G. H.; BENEDINI, M.; PAULA, F. B.; CHAGAS, R. C. S. Cimento como fonte de silício para a cana-de-açúcar. Stab, Piracicaba, v. 19, n. 2, p. 30-33, 2000.

KORNDÖRFER, G. H.; DATNOFF, L. E. Adubação com silício: uma alternativa no controle de doenças da cana-de-açúcar e do arroz. Informações Agronômicas, Piracicaba, n. 70, p. 1-5, jun. 1995.

MA, J. F.; MIYAKE, Y.; TAKAHASHI, E. Silicon as a beneficial element for crop plant. In: DATNOFF, L. E.; KORNDÖRFER, G. H.; SNYDER, G. Silicon in agriculture. New York: Elsevier Science, 2001. p. 17-39.

POZZA, A. A. A.; ALVES, E.; POZZA, E. A.; CARVALHO, J. G.; MONTANARI, M.; GUIMARÃES, P. T. G.; SANTOS, D. M. Efeito do silício no controle da cercosporiose em três cultivares de cafeeiro. Fitopatologia Brasileira. Brasília, v. 29, n. 2, mar./abr. 2004.

SANGSTER, A. G.; HODSON, J.; TUBB, H. J. Silicon deposition in higher plants. In: DATNOFF, L. E.; KORNDÖRFER, G. H.; SNYDER, G. H. (Ed.). Silicon in agriculture. Amsterdam: Elsevier, 2001. p. 85-113. (Studies in plant science, 8).

SÁVIO, F. L.; SILVA, G. C.; TEIXEIRA, I. R.; BORÉM, A. Produção de biomassa e conteúdo de silício em gramíneas forrageiras sob diferentes fontes de silicato. Semina: Ciências Agrárias, Londrina, v. 32, n. 1, p. 103110, jan./mar. 2011.

SU, R. Z.; LIU, Z. M.; LI, J.; AI, J. Study on silica distribution of wheat straw surface. Scientia Silvae Sinicae, Beijing, v. 38, n. 6, p. 99-102, 2002.

SYLVESTER-BRADLEY, R; SCOTT, R. K.; WRIGHT, C. E. Physiology in the production and improvement of cereals. Home-Grown Cereals Authority Research Review 18. London: HGCA, 1990.

TAKAHASHI, E.; MA, J. F.; MIYAKE, Y. The possibility of silicon as an essential element for higher plants. Comments on Agricultural and Food Chemistry, Davis, v. 2, n. 2, p. 99-122, 1990.

WINSLOW, M. D. Silicon, disease resistance and yield of rice genotypes under upland cultural conditions. Crop Science, Madison, v. 32, n. 5, p. 1208-1213, set./out. 1992. 